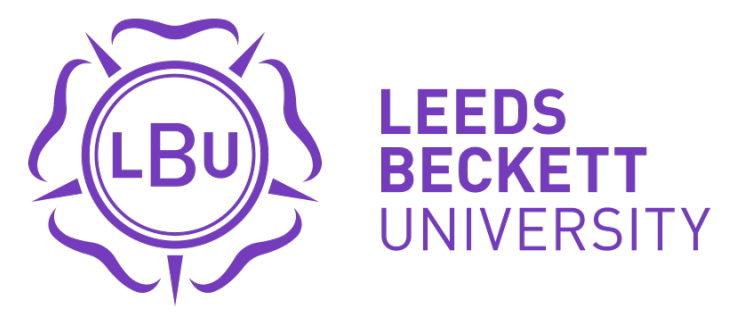

Citation:

Mackey, J and Mellor, A and Watchorn, J and Burnett, A and Boot, C and Woods, D (2016) The adrenocortical response to synthetic ACTH following a trek to high altitude. Hormone and Metabolic Research, 48 (10). pp. 658-663. ISSN 1439-4286 DOI: https://doi.org/10.1055/s-0042-112816

Link to Leeds Beckett Repository record:

https://eprints.leedsbeckett.ac.uk/id/eprint/3019/

Document Version:

Article (Accepted Version)

The aim of the Leeds Beckett Repository is to provide open access to our research, as required by funder policies and permitted by publishers and copyright law.

The Leeds Beckett repository holds a wide range of publications, each of which has been checked for copyright and the relevant embargo period has been applied by the Research Services team.

We operate on a standard take-down policy. If you are the author or publisher of an output and you would like it removed from the repository, please contact us and we will investigate on a case-by-case basis.

Each thesis in the repository has been cleared where necessary by the author for third party copyright. If you would like a thesis to be removed from the repository or believe there is an issue with copyright, please contact us on openaccess@leedsbeckett.ac.uk and we will investigate on a case-by-case basis. 


\section{The adrenocortical response to synthetic ACTH following a trek to high altitude.}

Joshua Mackey ${ }^{1}$, Adrian Mellor ${ }^{2,3,4}$, James Watchorn ${ }^{5}$, Anne Burnett ${ }^{6}$, Chris Boot ${ }^{6}$, David Woods ${ }^{2,3,7}$.

${ }^{1}$ Newcastle University.

${ }^{2}$ Royal Centre for Defence Medicine, Birmingham, B15 2 SQ.

${ }^{3}$ School of Sport, Carnegie faculty, Leeds Beckett University, Leeds, LS6 3QS.

${ }^{4}$ James Cook University Hospital, Middlesbrough.

${ }^{5}$ Intensive Care Department, Royal Berkshire Hospital, Reading

${ }^{6}$ Blood Sciences, Royal Victoria Infirmary, Newcastle, NE1 4LP.

${ }^{7}$ Northumbria NHS Trust and Newcastle NHS Trust.

Short running title: Synacthen testing at high altitude

Corresponding author: David Woods

\section{Address of corresponding author:}

Department of Endocrinology, Wansbeck General Hospital, Northumberland NE63 9JJ. e-mail: DoctorDRWoods@aol.com

Tel: 01670564022

\section{Author affiliations and addresses:}

Joshua Mackey, Medical Student, Newcastle University. joshmackey2512@gmail.com.

Adrian Mellor, Senior Lecturer, Academic Department of Military Anaesthesia and Critical Care. Medicine, RCDM, Birmingham. Visiting Professor Leeds Beckett University. dramellor@aol.com. James Watchorn, Intensive Care and Nephology Specialist Registrar, Royal Berkshire Hospital, Reading. jim.watchorn@doctors.org.uk

Anne Burnett, Clinical Scientist, Royal Victoria Infirmary, Newcastle. Anne.burnett@nuth.nhs.uk.

Chris Boot, Consultant Clinical Scientist, Royal Victoria Infirmary, Newcastle.

christopher.boot@nuth.nhs.uk.

David Woods, Consultant Endocrinologist, Reader in Military Medicine, RCDM and Professor of Sport and Exercise Endocrinology, Leeds Beckett University. DoctorDRWoods@aol.com. 


\section{Abstract}

Background: Gradual ascent to high altitude is typically associated with reduced resting aldosterone and unchanged cortisol, features that may facilitate acclimatization but are poorly understood.

Aims: To investigate the cortisol and aldosterone response to adrenocorticotrophic hormone at altitude.

Methods: Eleven subjects underwent a $250 \mu \mathrm{g}$ short synacthen test at sea-level and again after trekking to $3600 \mathrm{~m}$ in Nepal. Cortisol and aldosterone were measured by conventional assay from blood samples taken immediately prior to the administration of synacthen (T0) and then 30 (T30) and 60 (T60) minutes later.

Results: At 3600 m resting basal cortisol and aldosterone levels were both significantly lower than they were at sea-level ( $p=0.004, p=0.003$ respectively). Cortisol values at T30 and T60 were no different between sea-level and $3600 \mathrm{~m}$ but the increment after synacthen was significantly $(p=0.041)$ greater at $3600 \mathrm{~m}$ due to a lower basal value. Aldosterone at T30 and T60 was significantly lower ( $p=0.003$ for both) at $3600 \mathrm{~m}$ than at sea-level and the increment following synacthen was also significantly ( $p=0.003$ ) less at $3600 \mathrm{~m}$.

Conclusions: At $3600 \mathrm{~m}$ there appears to be a divergent adrenal response to synthetic adrenocorticotrophic hormone with an intact cortisol response but a reduced aldosterone response, relative to sea-level. This may reflect a specific effect of hypoxia on aldosterone synthesis and may be beneficial to acclimatization.

Keywords: High altitude, Hypoxia, Cortisol, Aldosterone, Synacthen, ACTH 


\section{Introduction}

The adrenocortical hormones aldosterone and cortisol contribute to fluid and sodium retention via their action on mineralocorticoid receptors in the renal nephron. Acclimatization to high altitude $(\mathrm{HA})$ is associated with a natriuresis and a diuresis [1]. With gradual ascent to HA resting cortisol levels typically remain unchanged [2-7] and have been noted to decrease [8]. Our own data [2] have shown no change until subjects are nearing extreme altitude where a rise in resting morning cortisol was noted at $5150 \mathrm{~m}$. Conversely, in studies in which subjects are rapidly exposed to hypoxic conditions, either in a hypoxic chamber or using a vehicle to ascend rapidly cortisol has been noted to increase [9-16]. Cortisol levels at HA have been shown to correlate with fluid retention [17] and the severity of acute mountain sickness (AMS) $[9,13]$. Gradual rather than rapid ascent, at least beneath altitudes of $5000 \mathrm{~m}$, may therefore prevent a rise in cortisol that could otherwise contribute to the fluid retention which is associated with $\operatorname{AMS}[1,18,19]$.

Resting adrenocorticotrophic hormone (ACTH) levels are elevated on acute exposure to hypobaric hypoxia equivalent to $3000 \mathrm{~m}$ without any difference in resting cortisol levels [3]. Sixty minutes of exercise in the same hypoxic conditions was also noted to produce an equivalent rise in ACTH to that seen in normoxia but with a blunted cortisol response. Together these findings suggest altered adrenal sensitivity to ACTH under hypoxic conditions. Post-mortem studies in high-altitude natives (HANs) have also suggested greater pituitary corticotroph numbers than in sea-level (SL) natives, along with physiological adrenal hyperplasia [20] again hinting at an altered relationship between ACTH and cortisol at HA. In support of this hypothesis it must be noted that the administration of corticotrophin releasing hormone to HANs at moderate altitude has been shown to induce a rise in ACTH but no subsequent increase in cortisol [21] and that HANs also demonstrate a subdued cortisol response to ACTH [22].

Most reports from both hypoxic chamber studies $[9,23,24]$ and field studies $[4,7,8,25,26]$, show a reduction in resting aldosterone at HA which is likely to be beneficial since it would facilitate a 
diuresis and a natriuresis. These findings are supported by in vitro studies, which have found that aldosterone production by adrenocortical cells in response to ACTH is significantly reduced in hypoxic conditions [27]. However, not all studies have reported a reduction in aldosterone upon ascent to HA and several which have reported a rise have found that the increase correlated closely with ACTH levels $[10,28,29]$. High levels of aldosterone at HA are associated with marked increases in total body water and plasma volume [30] and have been shown to correlate with the severity of AMS [28].

There are significant gaps in the literature regarding the adrenal response to HA. The cortisol response to ACTH has only been assessed following acute hypoxia or rapid ascent [7] and the aldosterone response to ACTH similarly has only been assessed following acute hypoxia and dexamethasone [31]. As we have discussed the rate of ascent can markedly affect the adrenal response to altitude. In reality most people ascending to altitude will do so by following a recognised trekking profile. Therefore, the most appropriate way to investigate any change in the adrenal response to $\mathrm{HA}$ is to do so during a typical trek. We therefore aimed to assess cortisol and aldosterone levels at rest at SL and following a typical trek to HA. Cortisol is primarily under the control of ACTH and while aldosterone is predominantly under the control of the RAS it does demonstrate a response to ACTH -[32] We therefore also aimed to assess the adrenal response following stimulation with synthetic ACTH (synacthen) at SL and HA.

\section{Materials and methods:}

\section{Ethical approval}

Ethical approval (protocol 579/MODREC/14) was granted by the Ministry of Defence Research Ethics Committee, Whitehall, UK, and research was conducted in accordance with the Declaration of Helsinki. All subjects gave written, informed consent before testing and an independent medical officer was present at all times. 


\section{Subjects and ascent profile}

Twelve serving UK military personnel (9 male, 3 female) who were taking part in an expedition to the Dhaulagiri Circuit in Western Nepal were recruited to take part in the study. None of the participants had been exposed to HA in the 6 months prior to the study, had a significant history of any HA illnesses or took any medication to aid acclimatisation. Exclusion criteria included any significant medical condition or the taking of any medication that may affect cortisol or aldosterone (such as anti-hypertensives). Participants flew from SL in the UK to Kathmandu (1300 m) and reached Italian Base Camp (3600 m) on Dhaulagiri I's West face by foot 10 days later after following a gradual ascent profile.

\section{AMS scores and basic physiological observations}

Scores of AMS and measures of resting systolic and diastolic blood pressure (SBP, DBP), heart rate $(\mathrm{HR})$, respiratory rate $(\mathrm{RR})$ and oxygen saturation $\left(\mathrm{SpO}_{2}\right)$ were recorded every morning and evening during the expedition until participants started to descend on day 12. Participants recorded their own AMS scores using the Lake Louise Score (LLS) questionnaire [33]. BP was recorded using an Omron M6 automatic BP monitor (Omron Healthcare, UK). $\mathrm{SpO}_{2}$ and $\mathrm{HR}$ were recorded using a Nellcor NP-20 handheld pulse oximeter (Covidian, MA, USA). RR was recorded manually by observing chest rise and fall.

\section{Short synacthen test (SST)}

Baseline testing was performed in the UK at SL $(220 \mathrm{~m}$ or $350 \mathrm{~m})$ one month prior to the beginning of the expedition. HA testing was performed at $3600 \mathrm{~m}, 48$ hours after arriving at that altitude. A 20 G cannula was inserted in to the ante-cubital fossa of participants and basal (T0) samples of $4 \mathrm{ml}$ venous blood were drawn into one serum separation tube vacutainer and one EDTA vacutainer. 250 $\mu g$ synacthen was then administered through the cannula and flushed. Further $4 \mathrm{ml}$ venous blood samples were collected through the cannula at 30 minutes (T30) and 60 minutes (T60) post- 
synacthen administration. Both SL and HA SST were performed at the same time of day (09:30) on well-rested subjects who had eaten a light breakfast 1 hour previously. Fluid intake during the expedition was not restricted or monitored but participants refrained from caffeine during the mornings before testing. During testing participants remained at rest in a seated position and refrained from eating or drinking. HA testing was performed in a tent where the ambient temperature was $17^{\circ} \mathrm{C}$.

\section{Laboratory analysis}

Blood samples were immediately centrifuged and the serum and plasma stored in cryovials that were frozen at minus $20^{\circ} \mathrm{C}$. One unintended freeze-thaw cycle occurred due to interruption of the power supply while on the mountain. Samples were analysed in the Clinical Biochemistry department, Royal Victoria Infirmary, Newcastle upon Tyne, UK. Serum sodium, potassium, urea, creatinine and osmolality were assayed by conventional means on baseline samples from SL and $3600 \mathrm{~m}$. Cortisol assays were performed using the Roche Elecsys Cortisol I assay on serum samples. The test is a competitive chemiluminescence immunoassay (CLIA) and is fully automated, run on the Roche modular E unit (Roche Diagnostics, Burgess Hill, UK). The analytical range of the assay is 0.5 $1750 \mathrm{nmol} / \mathrm{L}$. Low levels are reported as " $<20 \mathrm{nmol} / \mathrm{L}$ ". The lower detection limit of $0.5 \mathrm{nmol} / \mathrm{L}$ represents the lowest measurable analyte level that can be distinguished from 0 . There is an intraassay coefficient of variation (CV) of $9.3-11.7 \%$. The functional sensitivity of the assay is $<8.5 \mathrm{nmol} / \mathrm{L}$. Aldosterone assays were performed using the IDS iSYS assay on plasma samples collected using EDTA vacutainers. The assay is a CLIA and is fully automated, run on the IDS iSYS immunoassay analyser (IDS PLC, Boldon, UK). It has an analytical range of 103-3656 pmol/L with low levels being reported as " $<103 \mathrm{pmol} / \mathrm{L}$ ". The lower limit of quantification represents the lowest concentration of analyte that can be measured with acceptable precision. There is an intra-assay CV of $5.8-12.1 \%$. 
Following the expedition an investigation into the effect of an additional freeze-thaw cycle on aldosterone values was undertaken using 33 anonymised patient samples that had been submitted for routine aldosterone measurement.

\section{Statistical analysis}

Statistical analysis of the results was performed using SPSS 18.0 software. Data were examined for normal distribution using the Kolmogorov-Smirnov and Shapiro-Wilk tests. Normally distributed data are described using the mean and standard deviation (SD) whilst non-normally distributed data are described using the median and range. Comparisons of normally distributed paired data were done using the paired t-test. When one or both sets of paired data were not normally distributed comparisons were made using the Wilcoxon Signed Ranks test. Pearson's correlation coefficient or Spearman's correlation coefficient were calculated according to data distribution. A p-value of $<0.05$ was considered to be significant. Data for males and females were analysed together as there was no significant difference between sexes.

\section{Results:}

Medical screening revealed that one participant had a history of nephrectomy for chronic pyelonephritis with secondary hypertension and their data were excluded. The remaining 9 male and 2 female subjects were $25.9 \pm 2.5$ years old, weighed $73.2 \pm 7.8 \mathrm{~kg}$ and were $172.6 \pm 5.4 \mathrm{~cm}$ tall with a body mass index of $24.5 \pm 1.5 \mathrm{~kg} / \mathrm{m}^{2}$.

$\mathrm{SpO}_{2}(\%)$ was significantly lower $(p<0.0005)$ at $3600 \mathrm{~m}$ than it was at $1300 \mathrm{~m}(92.2 \pm 2.2$ vs 98.01 .0$)$. Between SL and 3600 basal serum sodium ( $140.3 \pm 2$ vs $141 \pm 2, \mathrm{mmol} / \mathrm{l}, \mathrm{p}=0.2)$; creatine $(88.3 \pm 13$ vs $89.2 \pm 14, \mathrm{umol} / \mathrm{l}, \mathrm{p}=0.9)$ and osmolality $(282.9 \pm 2.8 \mathrm{vs} 281.8 \pm 2.5, \mathrm{mosmol} / \mathrm{kg}, \mathrm{p}=0.3)$ did not change. Between SL and $3600 \mathrm{~m}$ basal potassium rose significantly $(4.37 \pm 0.2$ vs $4.62 \pm 0.3, \mathrm{mmol} / \mathrm{l}, \mathrm{p}=0.04)$ and urea fell significantly $(5.33 \pm 1$ vs $3.1 \pm 1, \mathrm{mmol} / \mathrm{l}, \mathrm{p}<0.01)$. 
The change in cortisol with SST is shown in Figure 1. The increase in cortisol from T0-T30, T0-T60 and T30-T60 was significant at both SL and $3600 \mathrm{~m}(\mathrm{p}<0.0005)$. Basal (T0) cortisol (nmol/l) was significantly lower $(p=0.004)$ at $3600 \mathrm{~m}$ than at SL $(373.6 \pm 59.8$ vs $477.6 \pm 97.9)$. Cortisol at $\mathrm{T} 30$ and T60 was not significantly different at $3600 \mathrm{~m}$ compared to SL. The increase in cortisol [nmol/l, median (range)] from T0-T30 was significantly greater $(Z=-2.491, p=0.013)$ at $3600 \mathrm{~m}$ than at $\mathrm{SL}$ [410(319-489) vs 312(221-564)] and the increase in cortisol from T0-T60 was also significantly greater $(p=0.041)$ at $3600 m$ than at SL [572(492-655) vs 482(395-765)].

At $3600 \mathrm{~m}$ the concentration of aldosterone in 18/33 samples fell below the lower limit of quantification of the assay (103 pmol/L). These results were assigned a value of $103 \mathrm{pmol} / \mathrm{L}$ to allow for statistical analysis and graphical representation. Aldosterone values following SST at SL and 3600 $\mathrm{m}$ are presented in Figure 2. Following the administration of synacthen at $\mathrm{SL}$ there was a significant increase in aldosterone from T0-30 and T0-60 ( $\mathrm{Z}=-2.934, \mathrm{p}=0.003$ for both tests). Basal (T0) aldosterone [pmol/L, median (range)] was significantly lower ( $\mathrm{Z}=-2.934, \mathrm{p}=0.003)$ at $3600 \mathrm{~m}$ than at SL [103(103-142) vs 234(167-520)]. Aldosterone at T30 and T60 was also significantly lower (Z=2.934, $p=0.003$ for both tests) at $3600 \mathrm{~m}$ than at SL [138(103-448) vs $806(366-1833)$ and $120(103-$ 389) vs 755(420-1753)]. The increase in aldosterone [pmol/L, median (range)] from T0-T30 was significantly lower $(Z=-2.934, p=0.003)$ at $3600 \mathrm{~m}$ than at $\mathrm{SL}[35(0-306)$ vs $517(199-1313)]$. The increase in aldosterone from T0-60 was also significantly lower $(Z=-2.934, p=0.003)$ at $3600 \mathrm{~m}$ than at SL [17(0-247) vs 520(253-1233)].

Investigation of the effect of an additional freeze-thaw cycle on values of aldosterone assayed after an additional freeze-thaw cycle showed excellent correlation with a linearity of $y=0.9748 x+3.8211$.

At $3600 \mathrm{~m}$ basal cortisol inversely correlated with $\mathrm{SpO}_{2}\left(r_{p}=-0.658, p=0.028\right)$ and the increase in cortisol from T0-T30 positively correlated with $\mathrm{SpO}_{2}\left(\mathrm{r}_{\mathrm{s}}=0.758, \mathrm{p}=0.007\right)$ as did the increase in cortisol from T0-T60 $\left(r_{s}=0.817, p=0.002\right)$. 
None of the AMS scores recorded by subjects using the LLS were above the threshold for diagnosing AMS on any occasion during the expedition.

\section{Discussion}

To our knowledge this is the first study to report the adrenal response to synthetic ACTH at HA following a gradual ascent by means of trekking. We have demonstrated that while the adrenal response to ACTH in terms of cortisol remains intact the aldosterone response is subdued. We also demonstrated, in line with previous reports, a fall in resting aldosterone at HA and a less frequently reported fall in resting cortisol.

Adrenocortical sensitivity to ACTH at HA has only been previously evaluated under acute hypoxic conditions or following rapid vehicular ascent. As discussed in the introduction the rate of ascent has a significant influence on the cortisol response to HA and our data more closely reflects the effect of the real-world scenario of trekking.

Our data regarding cortisol are consistent with a report from 1982 [7] concerning three subjects that showed no difference in plasma cortisol or 24 hour urine free cortisol in response to synacthen (250 $\mu \mathrm{g} I \mathrm{M}$ ) between SL and 3 days after being driven for 5 hours to $4350 \mathrm{~m}$. Similarly, it was reported in 1966 [34] that 12 subjects taken by train (10.5 hours) from SL to 4350 m demonstrated an intact adrenal response (as assessed by 24-hour urine measurements of 17-ketosteroids) to two injections of intramuscular ACTH (80 units) given 12 hours apart.

Our findings regarding a subdued aldosterone response to ACTH are also in line with a study [31] that administered low-dose synacthen $(0.125 \mu \mathrm{g}, 0.25 \mu \mathrm{g}, 0.5 \mu \mathrm{g}$ and $1.25 \mu \mathrm{g})$ following dexamethasone at $S L$ in normoxia and then while breathing a hypoxic gas mixture designed to reduce $\mathrm{SpO}_{2}$ to $90 \%$. The authors of this study reported a significant reduction in the aldosterone response to ACTH under the hypoxic conditions with an intact cortisol response. 
It is interesting to note that in rats severe hypoxia specifically inhibits (in vitro) adrenal aldosterone synthesis and aldosterone synthase mRNA without a change in other mitochondrial cytochrome P450 enzyme activities with a reduction in corticosterone conversion to aldosterone [35]. In addition, in vitro bovine adrenocortical cells exposed to hypoxia demonstrate a selective reduction in ACTHstimulated aldosterone production while maintaining an intact cortisol response [27]. Taken together these in vitro data offer a plausible explanation as to why we found an intact cortisol response but a subdued aldosterone response to $\mathrm{ACTH}$ in humans at $\mathrm{HA}$.

The finding that basal cortisol was significantly lower at $3600 \mathrm{~m}$ than at SL supports the hypothesis that following a gradual ascent, cortisol levels are lower at HA than they are at SL. It is also consistent with the findings of McLean et al. [8] who reported a significant drop in basal cortisol as high as $4500 \mathrm{~m}$. The results are contrary to the findings of several other papers which have reported an increase in cortisol upon rapid ascent to HA in both field [12-16] and chamber studies [9-11] and probably reflect that the adrenal cortisol response to hypoxaemia is highly dependent on the rate of ascent. It is highly unlikely that any fluctuation in cortisol at the altitude we used would significantly affect aldosterone levels since even high doses of prednisolone demonstrate no effect on basal aldosterone [36]

The finding that basal aldosterone was significantly lower at HA supports the hypothesis that, following a gradual ascent to HA, plasma levels of the hormone are lower than they are at SL. These findings concur with the bulk of HA field studies $[4,7,8,25,26]$ though this is not a universal finding $[24,37,38]$. Aldosterone release may be inhibited by a fall in potassium or an increase in blood volume but our findings that basal potassium rose slightly while osmolality did not change would be against these factors having an influence at $\mathrm{HA}$.

While the numbers are too small to rely on correlation analysis it is interesting to note the inverse correlation between $\mathrm{SpO}_{2}$ and basal cortisol at $3600 \mathrm{~m}$. It is possible that this may relate to sympathetic interaction with the hypothalamic-pituitary-adrenal axis due to hypoxia whilst the 
positive correlation between $\mathrm{SpO}_{2}$ and the rise in cortisol post-synacthen may reflect those with a higher $\mathrm{SpO}_{2}$ having lower basal cortisol levels and an intact adrenocortical reserve.

In conclusion, following a gradual ascent to $3600 \mathrm{~m}$, we found both cortisol and aldosterone levels to be lower than at SL. The response to SST suggests that while the cortisol response to ACTH remains intact at altitude the aldosterone response appears to be subdued. This raises the possibility that hypoxaemia is capable of selectively inhibiting ACTH-stimulated aldosterone secretion in humans. This may reflect a beneficial response to HA that facilitates acclimatization and reduces the risk of fluid retention.

We can only speculate on potential mechanisms for our current observations and further investigation is warranted. Future studies could interrogate the effects of HA on adrenal function further by incorporating assay of cortisol and aldosterone precursors as well as aspects of the RAS such as angiotensin II. In addition, investigation of other adrenal hormones that are under ACTH control, such as androstenedione and DHEAS would provide further useful information. Finally, more potent stimulation of adrenal aldosterone secretion could be obtained using infusion of angiotensin II.

\section{Limitations}

We acknowledge that this study has several limitations. Basal ACTH levels were not measured so it is not known whether the low basal cortisol and aldosterone levels measured at $3600 \mathrm{~m}$ are a product of low ACTH levels, adrenocortical blunting to ACTH or a combination of both. While we acknowledge that cortisol is primarily under the control of ACTH and aldosterone under the RAS [32] we still have clearly shown that synacthen induces a significant rise in aldosterone at $S L$ and that this is significantly blunted at $\mathrm{HA}$, unlike the cortisol response to synacthen.

We had originally intended to perform SST at additional altitudes of $4200 \mathrm{~m}$ and $5000 \mathrm{~m}$ but due to severe snowfall it was unsafe for the team to ascend higher. Partly as a result of severe weather 
conditions it became a challenge to maintain power to the freezer from the generator. While it is clearly desirable to avoid unnecessary freeze-thaw cycles in any assay we sustained an un-intended freeze-thaw cycle while in Nepal. On return to the UK we performed aldosterone assays on a patient cohort of 33 subjects following an additional freeze-thaw cycle and obtained reassuring results regarding the stability of aldosterone under such circumstances. This is supported by data showing that, having subjected aldosterone samples to two and three freeze-thaw cycles, values were still within $96.8-105.2 \%$ of the original [39]. Other workers have also reported that three freeze-thaw cycles have very little effect on the concentrations recorded of multiple hormones [40] and in one extreme, following 10 freeze-thaw cycles, aldosterone was only found to drop by $6.2 \%$ [41]. As best we can, therefore, we feel our data are a true reflection on the effect of HA.

Finally, while we did perform SST at SL we did not perform SST at SL after a ten-day trek at SL. While we therefore cannot fully exclude a confounder of exercise on our results we think any effect would be minimal since the subjects were well rested for 48 hours at $3600 \mathrm{~m}$ before SST was performed.

\section{Legends of tables and figures:}

Figure 1: Bar chart of mean plasma cortisol at SL and $3600 \mathrm{~m}$ clustered by time (0 min (basal), 30 mins or 60 mins) during the SST.

Figure 2: Bar chart of mean plasma aldosterone at SL and $3600 \mathrm{~m}$ clustered by time ( 0 min (basal), 30 mins or 60 mins) during the SST.

Figure 3: Correlation between serum aldosterone measured before and after an additional freezethaw cycle for 33 patient samples. Passing-Bablok regression line shown $(y=1.066 x+8.0)$.

Figure 4: Difference plot for serum aldosterone measured before and after an additional freezethaw cycle for 33 patient samples. 


\section{References}

1. Hackett PH, Rennie D, Grover RF, Reeves JT. Acute mountain sickness and the edemas of high altitude: a common pathogenesis? Respir Physiol. 1981; 46: 383-390.

2. Woods DR, Davison A, Stacey M, Smith C, Hooper T, Neely D, Turner S, Peaston R, Mellor A. The cortisol response to hypobaric hypoxia at rest and post-exercise. Horm Metab Res. 2012; 44: 302.

3. Bouissou P, Fiet J, Guezennec CY, Pesquies PC. Plasma adrenocorticotrophin and cortisol responses to acute hypoxia at rest and during exercise. Eur J Appl Physiol Occup Physiol. 1988; 57: 110-113.

4. Maher JT, Jones $L G$, Hartley LH, Williams $G H$, Rose LI. Aldosterone dynamics during graded exercise at sea level and high altitude. J Appl Physiol. 1975; 39: 18-22.

5. Basu M, Pal K, Prasad R, Malhotra AS, Rao KS, Sawhney RC. Pituitary, gonadal and adrenal hormones after prolonged residence at extreme altitude in man. Int J Androl. 1997; 20: 153-158.

6. Benso A, Broglio F, Aimaretti G, Lucatello B, Lanfranco F, Ghigo E, Grottoli S. Endocrine and metabolic responses to extreme altitude and physical exercise in climbers. Eur J Endocrinol. 2007; 157: $733-740$.

7. Keynes RJ, Smith GW, Slater JDH, Brown MM, Brown SE, Payne NN, Jowett TP, Monge CC. Renin and aldosterone at high altitude in man. J Endocrinol. 1982; 92: 131-140.

8. McLean CJ, Booth CW, Tattersall T, Few JD. The effect of high altitude on saliva aldosterone and glucocorticoid concentrations. Eur J Appl Physiol Occup Physiol. 1989; 58: 341-347.

9. Sutton JR, Viol GW, Gray GW, McFadden M, Keane PM. Renin, aldosterone, electrolyte, and cortisol responses to hypoxic decompression. J Appl Physiol. 1977; 43: 421-424.

10. Okazaki S, Tamura Y, Hatano T, Matsui N. Hormonal disturbances of fluid-electrolyte metabolism under altitude exposure in man. Aviat Space Environ Med. 1984; 55: 200-205. 
11. Kraemer WJ, Hamilton AJ, Gordon SE, Trad LA, Reeves JT, Zahn DW, Cymerman A. Plasma changes in beta-endorphin to acute hypobaric hypoxia and high intensity exercise. Aviat Space Environ Med. 1991; 62: 754-758.

12. Humpeler E, Skrabal F, Bartsch G. Influence of exposure to moderate altitude on the plasma concentration of cortisol, aldosterone, renin, testosterone, and gonadotropins. Eur J Appl Physiol Occup Physiol. 1980; 45: 167-176.

13. Richalet J-P, Rutgers V, Bouchet $P$, Rymer J-C, Keromes A, Duval-Arnould G, Rathat $C$. Diurnal variations of acute mountain sickness, colour vision, and plasma cortisol and ACTH at high altitude. Aviat Space Environ Med. 1989.

14. Sawhney RC, Malhotra AS, Singh T. Glucoregulatory hormones in man at high altitude. Eur J Appl Physiol Occup Physiol. 1991; 62: 286-291.

15. Richalet J-P, Letournel $M$, Souberbielle J-C. Effects of high-altitude hypoxia on the hormonal response to hypothalamic factors. Am J Physiol Regul Integr Comp Physiol. 2010; 299: 1685-1692.

16. Larsen JJ, Hansen JM, Olsen NV, Galbo H, Dela F. The effect of altitude hypoxia on glucose homeostasis in men. J Physiol. 1997; 504: 241-249.

17. Heyes MP, Farber MO, Manfredi F, Robertshaw D, Weinberger M, Fineberg $N$, Robertson $G$. Acute effects of hypoxia on renal and endocrine function in normal humans. Am J Physiol Regul Integr Comp Physiol. 1982; 243: 265-270.

18. Loeppky JA, Icenogle MV, Maes D, Riboni K, Hinghofer-Szalkay H, Roach RC. Early fluid retention and severe acute mountain sickness. J Appl Physiol. 2005; 98: 591-597.

19. Hackett PH, Rennie D, Hofmeister SE, Grover RF, Grover EB, Reeves JT. Fluid retention and relative hypoventilation in acute mountain sickness. Respiration. 1982; 43: 321-329.

20. Gosney J, Heath D, Williams D, Rios-Dalenz J. Morphological changes in the pituitaryadrenocortical axis in natives of La Paz. Int J Biometeorol. 1991; 35: 1-5.

21. Ramirez $G$, Herrera R, Plneda D, Blttle PA, Rabb HA, Bercu BB. The effects of high altitude on hypothalamic-pituitary secretory dynamics in men. Clin Endocrinol (Oxf). 1995; 43: 11-18. 
22. Moncloa F, Pretell E. Cortisol secretion rate, ACTH and methopyrapone tests in high altitude native residents. J Clin Endocrinol Metab. 1964; 24: 915-918.

23. Bestle MH, Olsen NV, Poulsen TD, Roach R, Fogh-Andersen N, Bie P. Prolonged hypobaric hypoxemia attenuates vasopressin secretion and renal response to osmostimulation in men. J Appl Physiol. 2002; 92: 1911-1922.

24. Shigeoka JW, Colice GL, Ramirez G. Effect of normoxemic and hypoxemic exercise on renin and aldosterone. J Appl Physiol. 1985; 59: 142-148.

25. Olsen NV, Kanstrup I-L, Richalet JP, Hansen JM, Plazen G, Galen FX. Effects of acute hypoxia on renal and endocrine function at rest and during graded exercise in hydrated subjects. J Appl Physiol. 1992; 73: 2036-2043.

26. Zaccaria $M$, Rocco S, Noventa D, Varnier M, Opocher G. Sodium Regulating Hormones at High Altitude: Basal and Post-Exercise Levels 1. J Clin Endocrinol Metab. 1998; 83: 570-574.

27. Raff $H, B a l l D L$, Goodfriend TL. Low oxygen selectively inhibits aldosterone secretion from bovine adrenocortical cells in vitro. Am J Physiol Endocrinol Metab. 1989; 256: E640-E644.

28. Bartsch P, Maggiorini M, Schobersberger W, Shaw S, Rascher W, Girard J, Weidmann P, Oelz $O$. Enhanced exercise-induced rise of aldosterone and vasopressin preceding mountain sickness. J Appl Physiol. 1991; 71: 136-143.

29. Westendorp RG, Roos AN, Simons M, Wertheim W, Bosch FH, Frolich M, Meinders AE. Effects of hypoxia and atrial natriuretic peptide on aldosterone secretion in healthy subjects. J Appl Physiol. 1993; 75: 534-539.

30. Anand IS, Chandrashekhar Y, Rao SK, Malhotra RM, Ferrari R, Chandana J, Ramesh B, Shetty KJ, Boparai MS. Body fluid compartments, renal blood flow, and hormones at 6,000 $\mathrm{m}$ in normal subjects. J Appl Physiol. 1993; 74: 1234-1239.

31. Ramirez G, Bittle PA, Hammond M, Ayers CW, Dietz JR, Colice GL. Regulation of Aldosterone Secretion During Hypoxemia at Sea Level and Moderately High Altitude. J Clin Endocrinol Metab. 1988; 67: 1162-1165. 
32. Willenberg HS, Schinner S, Ansurudeen I. New mechanisms to control aldosterone synthesis. Horm Metab Res. 2008; 40:435-441.

33. Hackett $P H, O e l z O$. The Lake Louise consensus on the definition and quantification of altitude illness. Hypoxia and mountain medicine. 1992: 327-330.

34.. $\quad$ Moncloa F, Beteta L, Velazco I, Goñez C. ACTH Stimulation and Dexamethasone Inhibition in Newcomers to High Altitude. Exp Biol Med. 1966; 122: 1029-1031.

33.

35. Raff H, Jankowski BM, Engeland WC, Oaks MK. Hypoxia in vivo inhibits aldosterone synthesis and aldosterone synthase mRNA in rats. J Appl Physiol. 1996; 81: 604-610.

36. Collomp K, Zorgati H, Cottin F, Do MC, Labsy Z, Gagey O, Lasne F, Prieur F, Collomp R. Timecourse of prednisone effects on hormonal and inflammatory responses at rest and during resistance exercise. Horm Metab Res. 2015; 47:516-520.

36.

37. Slater JD, Tuffley RE, Williams ES, Beresford CH, Sönksen PH, Edwards RH, Ekins RP, McLaughlin M. Control of aldosterone secretion during acclimatization to hypoxia in man. Clin Sci. 1969; 37: 327-341.

38. Tuffley $R E$, Rubenstein $D$, Slater JDH, Williams ES. Serum renin activity during exposure to hypoxia. J Endocrinol. 1970; 48: 497-510.

39. Das R, Dan S, Pal TK. Method development and validation of liquid chromatographytandem/mass spectrometry for aldosterone in human plasma: Application to drug interaction study of atorvastatin and olmesartan combination. J Adv Pharm Technol Res. 2014; 5: 108.

40. Comstock GW, Burke AE, Norkus EP, Gordon GB, Hoffman SC, Helzlsouer KJ. Effects of repeated freeze-thaw cycles on concentrations of cholesterol, micronutrients, and hormones in human plasma and serum. Clin Chem. 2001; 47: 139-142.

41. Kley HK, Rick W. The effect of storage and temperature on the analysis of steroids in plasma and blood. J Clin Chem Clin Biochem. 1984; 22: 371-378. 
